\title{
Development of new functional seismic brace using partially fibred carbon fiber reinforced polymer
}

\author{
Yukihiro Matsumoto ${ }^{1 *}$, Takashi Taguchi ${ }^{2}$, Keisuke Shimizu ${ }^{2}$, Iwao Komiya ${ }^{3}$, and Koji Nakajima ${ }^{3}$ \\ ${ }^{1}$ Toyohashi University of Technology, Department of Architecture and Civil Engineering, Hibarigaoka 1-1 Tempaku-cho \\ Toyohashi Aichi, Japan \\ ${ }^{2}$ Yahagi Construction Co., Engineering Centre, Ibaragasama 1533-74 Nagakute Aichi, Japan \\ ${ }^{3}$ Fukui Fibertech Co., Iwanishi 5-1 Nakahara-Cho Toyohashi Aichi, Japan
}

\begin{abstract}
This study proposes a new tension member with a buckling-free function using carbon fiber reinforced polymer for the seismic bracing system. Firstly, the concept of the composite brace; a partially fibred carbon fiber reinforced polymer brace, is introduced. Secondly, the material strength of the composite brace molded by modified pultrusion is investigated. Finally, cyclic loading tests to simulate the seismic loading are conducted. As a result, it was demonstrated that a seismic brace system using the composite brace can provide buckling prevention and plastic deformation performance to absorb vibration energy.
\end{abstract}

\section{Introduction}

Carbon fiber reinforced polymer (CFRP) have been widely applied to the airplane, automobile, civil, and building engineering field, because of its excellent mechanical performance, i.e., high strength, high elastic modulus, lightweight, and good durability. In the civil engineering field, CFRP has been applied to repair and strengthening use [1], and new composite applications were developed in recent years [2]. It is well known that CFRP can resist large tensile force by its high fiber's tensile strength. It means that the effective use of CFRP with unidirectional fibers to take advantage of material characteristics is the use of tension members. Thus, a large number of researchers have been developed a composite tension member and its connection methods [3-5]. Schmidt et al. [3] show several anchorages methods and their mechanical performance to perform the tensile capacity of FRP tendons. And it is shown that mechanical anchorage using wedges is often adopted to prevent slippage and creep. Benmokrane et al. [4] show grouted anchor applications to evaluate the tensile properties of AFRP and CFRP. Xie et al. [5] reported the cyclic loading test results of CFRP tendons with a wedge-bonded anchor.

The authors have developed tension resistible and compression non-resistible member by partially fibred CFRP (PFCFRP) to prevent a buckling deformation and plastic strain concentration at both edges of the brace by buckling shown in Fig. 1. This paper shows the adapted molding method of PFCFRP and its material strength, connection method and its strength, and cyclic test results of the PFCFRP braces to clarify the mechanical properties for the structural design.

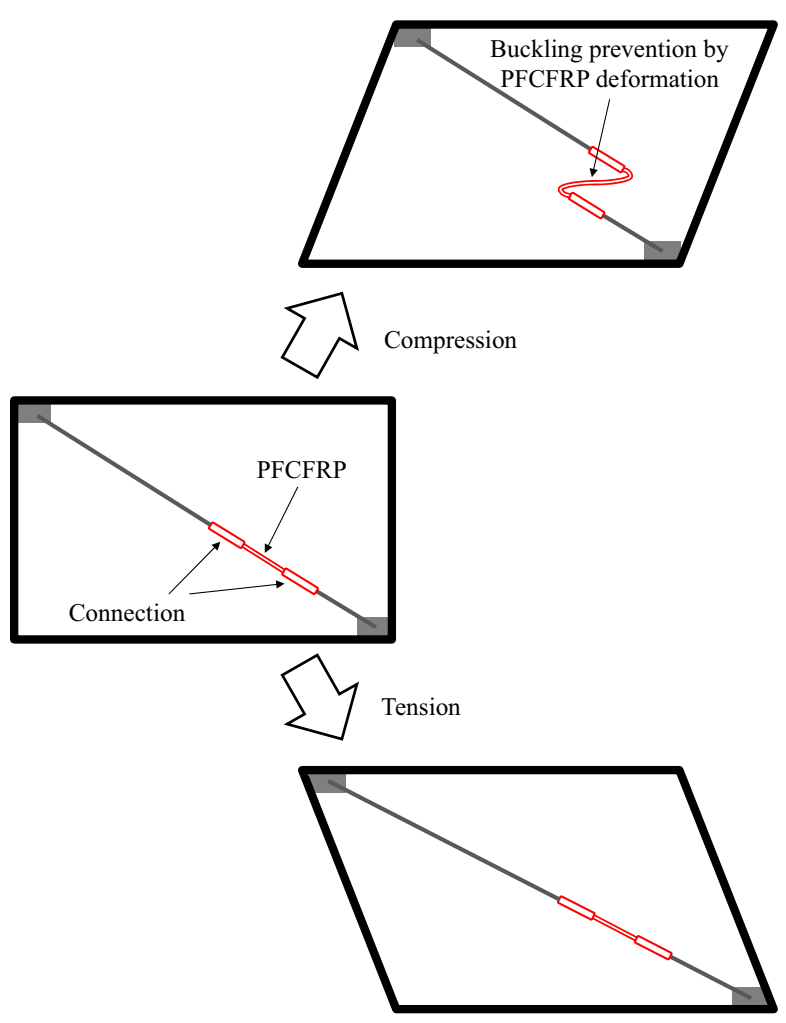

Fig. 1. Concept of new functional brace member.

\section{Partially fibred CFRP}

Fig. 2. shows the molding method of PFCFRP. We adopt the customized pultrusion to mold because pultrusion has some advantages; high productivity, stable properties, and

\footnotetext{
* Corresponding author: y-matsum@ace.tut.ac.jp
} 
high fiber content. Usually, carbon fiber passes through a resin bath to become CFRP. However, the authors added a new process that bypasses the resin bath to make a partially fibred position on pultruded CFRP as shown in Fig. 2. Thus, PFCFRP can be molded without loss of productivity by applying automatic cyclic movement. Table 1 shows the properties of CFRP. We adopted a large carbon tow (PX35, commercial product of Zoltek) to make CFRPs economically. Fig. 3 shows a PFCFRP rod with a $12 \mathrm{~mm}$ diameter. In total 33 carbon tows having 3750 texes were installed to the PFCFRP rod.

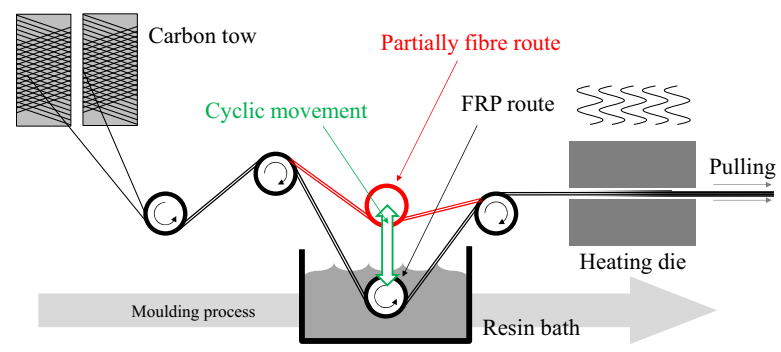

Fig. 2. The molding method of partially fibred carbon fiber reinforced polymer.

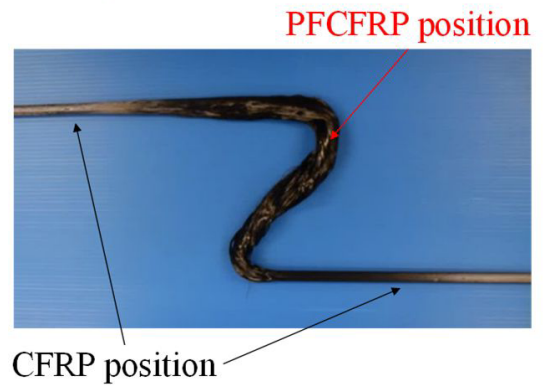

Fig. 3. Partially fibred carbon fiber reinforced polymer rod.

Table 1. CFRP properties.

\begin{tabular}{|c|c|}
\hline Carbon tow & PX35 \\
\hline Elastic modulus of CF & $242 \mathrm{GPa}$ \\
\hline Tensile strength of CF & $4.137 \mathrm{GPa}$ \\
\hline Matrix resin & Vinylester \\
\hline Fibre content & $60.5 \%$ \\
\hline Diameter & $12 \mathrm{~mm}$ \\
\hline
\end{tabular}

\section{Experiments}

\subsection{Material tensile tests}

This study aims to develop a new composite brace member. Thus, we have to clarify not only the material strength of PFCFRP but also the connection method and strength to apply. Therefore, we adopt a steel pipe-style turnbuckle body [6] at both edges for fixing of PFCFRP rod to simplify the connection like a sleeve connection as shown in Fig. 4. Because the thread on the side opposite to the PFCFRP rod of the turnbuckle body can be used for connection to the steel structure. Moreover, the use of a common connection method provides a possibility of replacement from existing steel turnbuckle braces to PFCFRP brace. Fig. 5 shows the experimental setup. In the case of material tests for CFRP, Fig. 5 (a), M30 steel pipe style turnbuckle body with $300 \mathrm{~mm}$ embedding length was adopted. An M20 turnbuckle body with 220 $\mathrm{mm}$ embedding length was adopted for material tests for PFCFRP shown in Fig. 5 (b). Moreover, in the case of tensile tests for connection strength, an M16 steel pipe style turnbuckle body with $100 \mathrm{~mm}$ embedding length and with the additional M16 bolt to simulate an actual connection condition was adopted shown in Fig. 5 (c).

Fig. 6. shows the maximum loading obtained by various tensile tests shown in Fig. 5. And nominal capacities of steel turnbuckle brace [6] and CFRP are also represented in Fig. 6. The material strength of CFRP using large carbon tow was evaluated as approximately $74 \%$ of nominal carbon fiber strength. And in the case of a fibred specimen, material strength was reduced to $54 \%$ of CFRP. However, it can be seen that the tensile strength of PFCFRP is higher than the strength of the steel turnbuckle body. Thus, the tensile strength of composite brace with $12 \mathrm{~mm}$ PFCFRP rod and M16 steel pipe style turnbuckle body can be evaluated by the strength of steel turnbuckle. Because the strength of steel turnbuckle body is perfectly managed to satisfy the nominal values; $83.1 \mathrm{kN}$ tensile strength in the case of M16 turnbuckle body. Furthermore, both buckling prevention and plastic deformation performance can be expected using the serially connected PFCFRP brace and steel brace shown in Fig. 1.

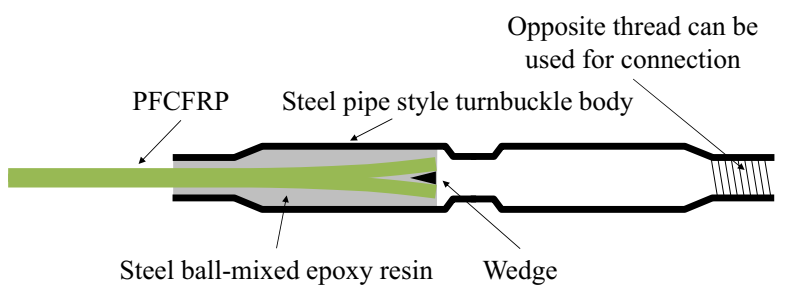

Fig. 4. Connection of PFCFRP and steel pipe-style turnbuckle body.

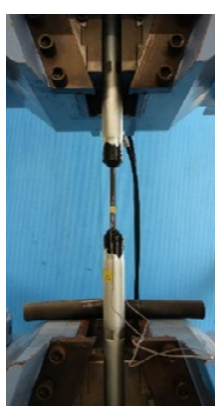

(a)

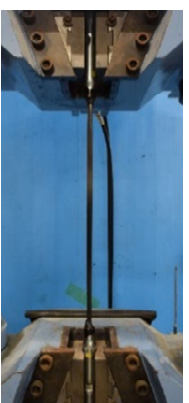

(b)

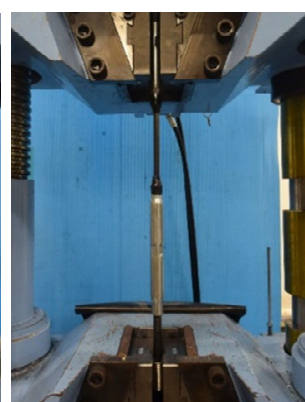

(c)
Fig. 5. Experimental setup: (a) CFRP material test; (b) PFCFRP material test; (c) Connection strength test. 
Load $[\mathrm{kN}]$

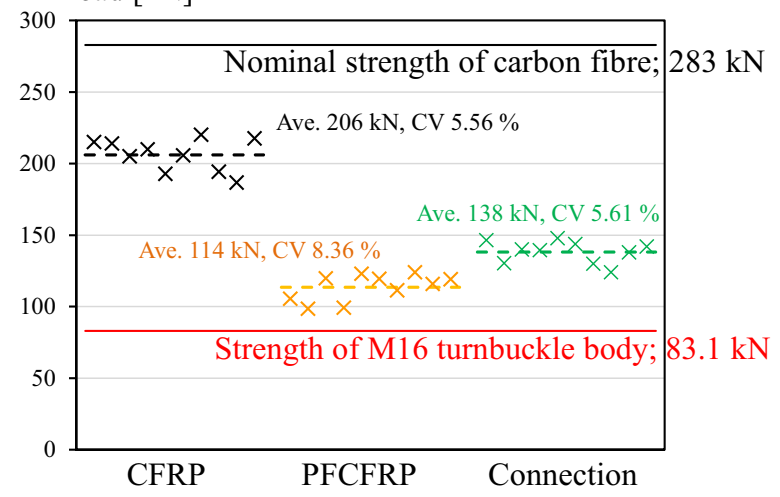

Fig. 6. Results of tensile test.

\subsection{Axial cyclic loading tests}

Table 2 and Fig. 7 show experimental parameter and experimental setup of longitudinal cyclic test, respectively. Fig. 8 shows deformation under compressive loading. In the case of steel brace, Fig. 8 (a), large lateral deformation occurred by buckling. This buckling deformation suggests that the steel brace will collide near structural members, finishing materials, and facilities when an earthquake occurs. On the other hand, steel and PFCFRP composite brace could maintain the shape of brace straight because PFCFRP absorbed a compressive deformation concentratedly shown in Fig. 8 (b). Fig. 9 shows axial load-deformation relations. Both steel and steel and PFCFRP composite brace performed plastic deformation. However, hardening of the M16-PF1 specimen occurred earlier than M16-S1 because the steel length of M16-PF1 is shortened by PFCFRP installation.

Table 2. Experimental parameter.

\begin{tabular}{|c|c|c|}
\hline Specimen name & M16-S1 & M16-PF1 \\
\hline Total length & \multicolumn{2}{|c|}{$3,000 \mathrm{~mm}$} \\
\hline PFCFRP length & N/A & $750 \mathrm{~mm}$ \\
\hline Turnbuckle size & \multicolumn{2}{|c|}{ M16 } \\
\hline
\end{tabular}

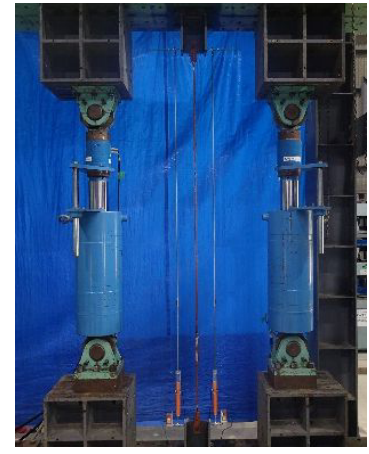

(a)

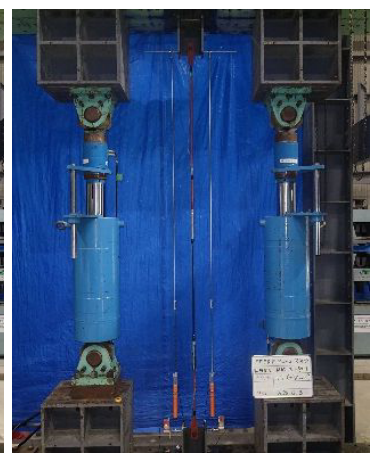

(b)

Fig. 7. Experimental setup: (a) Steel brace; (b) Steel and PFCFRP brace.

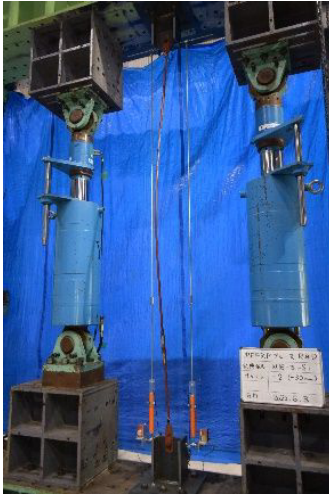

(a)

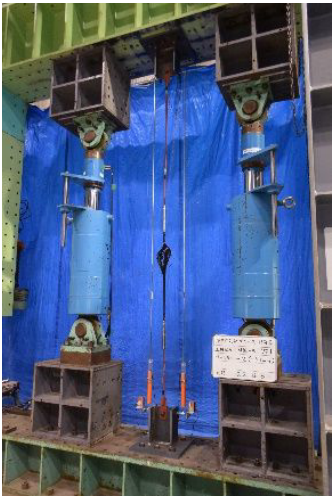

(b)
Fig. 8. Deformation under compressive loading: (a) Steel brace; (b) Steel and PFCFRP brace.

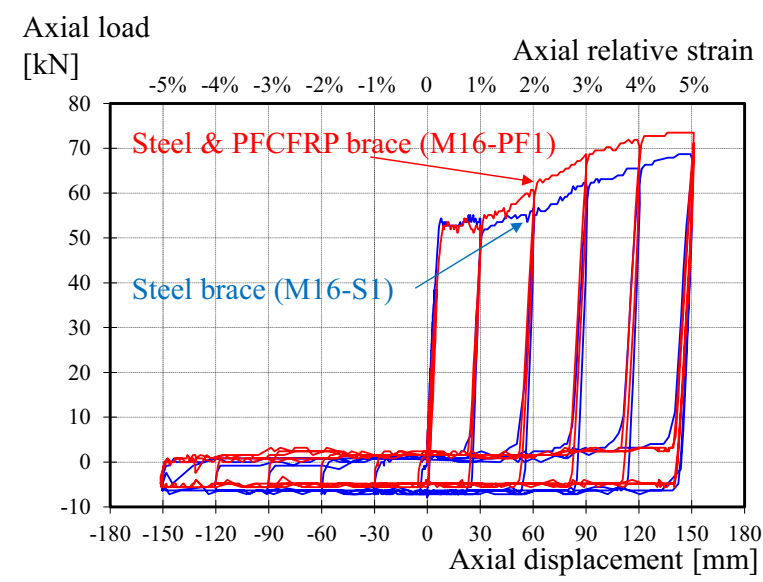

Fig. 9. Axial load-deformation relations.

\section{Conclusions}

This paper shows the fundamental material performance of CFRP and PFCFRP rods using large carbon tow molded by pulrusion. Then, a connection method using a steel pipe-style turnbuckle body for CFRP was proposed, and its connection strength was made clear. As the result, it was clarified that the PFCFRP rod with a $12 \mathrm{~mm}$ diameter has higher strength compared with the M16 turnbuckle body and turnbuckle main member. Thus, it was demonstrated that composite brace with steel and PFCFRP members can provide a function of buckling prevention and plastic deformation performance.

This research was funded by MLIT Construction Technology Research and Development Subsidy Program.

\section{References}

1. X.L. Zhao, L. Zhang, State-of-the-art review on FRP strengthened steel structures, Engineering Structures, 29, 8 (2007)

2. Composites Manufacturing website, http://compositesmanufacturingmagazine.com/2017/ 
10/ new-apple-store-Chicago-boasts-hugecomposite-roof/ (2017)

3. J.W. Schmidt, A. Bennitz, B. Tãljsten, P. Goltermanm, H. Pedersen, Mechanical anchorage of FRP tendons - A literature review, Construction and Building Materials, 32 (2012)

4. B. Benmokrane, B. Zhang, A. Chennouf, Tensile properties and pullout behavior of AFRP and CFRP rods for grouted anchor applications, Construction and Building Materials, 13, 3 (2000)

5. G.H. Xie, Y.L. Bian, Q.H. Feng, C.M. Wang, R.G. Liu, Experimental study on wedge-bonded anchors for CFRP tendons under cyclic loading, Construction and Building Materials, 236, 10 (2020)

6. Japan industrial standards, JIS A 5541: Body of turnbuckle for building (2008) 